\title{
Introduction: new directions in the study of work and employment
}

\section{Charles J. Whalen}

\section{INDUSTRIAL RELATIONS IN CRISIS}

Work and employment have been subjects of academic research and teaching for over a century. Their study emerged out of the examination of social problems and evolved into a field called industrial relations (IR), which was born in the United States around 1920. Since its inception, IR has generally been considered interdisciplinary terrain devoted to both science building and real-world problem solving (Kaufman, 2004).

In the current era, IR should be flourishing. Across the academy, one can find a growing recognition of the value of crossing traditional boundaries and engaging in interdisciplinary scientific research. Problems regarding jobs and employment relations, meanwhile, are a major concern for workers, managers and government representatives across the globe. As Bruce E. Kaufman writes at the conclusion of his sweeping history of the global evolution of IR, 'Who today would say that the subject of employment and contemporary developments in the world of work is less important today than two or three decades ago? Few, I wager, and most would probably say the opposite - that the world of work is more important than ever for peoples and nations across the globe' (Kaufman, 2004: 621).

Nevertheless, academic units devoted to IR are facing tough times especially in the English-speaking world - and the number of scholars associated with the field is shrinking. ${ }^{1}$ Many observers say the problem is that IR researchers became too focused on issues involving organized labor, especially collective bargaining, and thus the fortunes of the field faded over time with the erosion of union membership and power. Others tell a more complicated story that involves a number of decisions made by IR scholars (about the field's conceptual makeup, relationship to other fields, and research methods, for example) and the impact upon the field of a variety of social and institutional developments that have taken place outside IR academic units (see, for instance, Kaufman, 2004). There may be disagreements about the exact source of the problem, but what is clear 
is that the word 'crisis' is increasingly being used, and there has even been recent talk about the possibility of the field's extinction.

Letting IR wither and fade away is not a sensible option. No other field of academic inquiry is devoted exclusively to studying the world of work. Other fields often examine elements found in the IR realm, but the practical results are largely disappointing. As Michael J. Piore writes in chapter 9 of this volume, scholars in mainstream disciplines break up IR's 'key methodological and empirical issues into a series of separate components and parcel them out to different social sciences - disciplines that speak to each other in very limited and stylized ways or not at all. ... This leaves space in the intellectual landscape for a more integrated, interdisciplinary approach.' Indeed, the present era cries out for the insights of such an approach. It is for this reason that IR should be revitalized; society deserves a scholarly community devoted to the world of work.

To revitalize IR as an academic enterprise, new directions in the study of work and employment are needed. The scope and intellectual content of the field must be reconsidered; its institutions must be reinforced or reshaped; and cutting-edge conceptual and practical issues must receive attention in the course of revitalizing its practice. This volume, which developed out of a symposium held at the annual meeting of the Labor and Employment Relations Association (LERA) in 2007, identifies such new directions by assembling some of the field's most creative and insightful scholars.

Rethinking IR means reconnecting with its origin as a field grounded in an understanding of institutional and historical reality, concerned with all aspects of work, and populated by scholars committed to the resolution of pressing labor problems. IR can no longer be synonymous with the study of just unions and collective bargaining, which became the view of many in recent decades. It must be a broad expanse - conducive to theory development, open to a multiplicity of paradigms, and accommodative of the fact that employment relationships come in many varieties and can be structured to seek any of a diverse set of objectives. Chapters in Part 1 examine how this can be accomplished.

Rebuilding IR institutions must begin in the academy, as it exists today; IR scholars cannot sit tight and wait for social changes to occur first. Such rebuilding requires a hard look at the status of IR within centers of higher learning and construction of an aggressive plan for resurgence. In addition, there must be both introspection regarding the way the field judges its own scholarship and a reconsideration of the social impact of IR research. The rebuilding must also involve an effort to breathe new life into the legal framework and social institutions that structure employment relations for society at large. Chapters in Part 2 address these matters. 
Reenergizing IR practice involves recognizing that the performance and management of work now occurs in a dynamic, global economy that is different in many ways from the economy that existed immediately following World War II. This environment demands refashioned IR curricula. It also requires close scholarly attention to the interplay between worldwide trends (especially those involving or influencing international job and labor mobility), national economic systems, business and labor strategies, and employment-relations practices. Not all researchers must turn their attention from investigations of union-management relations in manufacturing to scholarship on service employment or emerging industries, but even the study of longstanding industries such as apparel must recognize the transnational realities faced by today's workers and employers. Chapters in Part 3 flesh out the issues at stake and examine specific developments and sectoral examples capable of moving the field forward. A concluding chapter by Thomas A. Kochan offers further thoughts on the future of the field in light of all the chapters that precede it.

\section{THE FIELD OF INDUSTRIAL RELATIONS}

Although the field of IR may not have emerged until the twentieth century, it bears a name that reveals deep roots traceable to the Industrial Revolution. In Chapter 1, Joel Cutcher-Gershenfeld reflects on the separate and joint use of the terms 'industrial' and 'relations,' and explains how they take on new and broader meaning in today's knowledge-driven economy. Cutcher-Gershenfeld admits he is not sure whether the IR label can adapt well to the new era and acknowledges that 'employment relations' is an alternative that more fully reflects the spectrum of contemporary workplace relationships. Nevertheless, a field's guiding principles are even more important than its name, and Chapter 1 demonstrates the enduring applicability of the principles adopted by IR scholars and academic units decades ago - namely, the need for blending theory, practice and policy; valuing balance between labor and management (now expanded to include other stakeholders as well); and assembling cross-disciplinary faculties.

Bruce Kaufman also finds that the history of the IR field contains a set of ideas with enduring value. In Chapter 2, he introduces those ideas as the 'original' IR paradigm, which emerged in the United States in the 1920s, and offers it as an alternative to the paradigm that treats IR as involving only the study of unions and union-management relations, a view holding a prominent place in the field since at least the 1970s. Since Kaufman sees no major resurgence of unions on the horizon, he argues that restructuring and repositioning IR according to its original paradigm is the best way to 
prevent the field from suffering further decline, especially in the United States.

The original IR paradigm has what Kaufman calls 'three faces' - a commitment to science building; a focus on practical problem solving; and a belief in the values of economic efficiency, social fairness, and human selfactualization. The core principle uniting these faces is that 'labor is not a commodity,' which can be stated alternatively as 'rejection of the orthodox competitive demand/supply labor market model as the appropriate framework' for analyzing the real world. The result is an expansive field, covering all aspects of the employment relationship and capable of including a wide range of scholars and practitioners, regardless of whether they specialize in labor-oriented, management-oriented, or policy-oriented solutions to employment problems.

While Kaufman's chapter calls for choosing between two paradigms, the present's narrow one and the past's more inclusive one, John W. Budd's recent scholarship has focused on finding a way to bridge IR's four 'schools of thought' (Budd, 2004). In Chapter 3, Budd presents those schools as each generating a distinctive model of the employment relationship. (He calls them the egoist, unitarist, pluralist, and critical employment-relations models; and they are associated with neoclassical economics, personnel or human resource management, institutional economics, and Marxism, respectively.) Budd's approach to the revitalization of IR involves not only spelling out and calling for widespread recognition of a meta-paradigm capable of encompassing the field's various models (paradigms), but also promoting dialogue among scholars with differing perspectives. The centerpiece of his approach is an emphasis on making IR objectives, assumptions and predictions explicit.

The views of Budd and Kaufman overlap in a number of important respects. For example, both place the whole employment relationship rather than just the study of unions - at the heart of IR. In addition, Budd's list of possible objectives of the employment relationship (which are what he deems the 'starting point' for IR scholarship) consists of efficiency, equity and voice, which closely parallel the elements Kaufman identifies as characteristic of the ethical/ideological face of the original IR paradigm. The authors also have a common aim: to recast IR as a broad field, open to diverse voices, and committed to science building and problem solving.

Chapter 4, by John Godard, extends the reconsideration of IR by emphasizing the need for a systematic study of the institutions of labor and employment. The central message of Godard's chapter is that an 'institutional environments' approach to IR research can help the field 'regain its intellectual bearings.' His chapter explains the tenets of such an approach and illustrates its usefulness by exploring two research examples: 
a comparative examination of the role of unions in Canada and England, and an inquiry into the exceptional decline of the US labor movement.

\section{THE INSTITUTIONS OF INDUSTRIAL RELATIONS}

Revitalizing IR requires reforming and reconstructing institutions as well as studying them. Chapter 5 sets the stage for a discussion of the latter by cataloging how the weakening of the US labor movement 'caused collateral damage to organizations and institutions that have a close relationship to unions.' In particular, co-authors David B. Lipsky and Ronald L. Seeber examine the 'social capital' implications of labor's decline upon federal agencies, neutral and professional associations (such as the LERA and the American Arbitration Association), university IR programs, and other organizations with a mission relating in some way to organized labor.

Now that the social network that helped to support the labor movement 'has substantially withered,' can a revitalization of unions occur? Lipsky and Seeber offer a nuanced answer. On the one hand, initiating and sustaining a union resurgence might be easier in the presence of institutions designed to support and foster labor's growth. On the other hand, US labor history indicates that successful union organizing and expansion do not require the existence of a large stock of social capital.

Of course, one institution that has played a major role in the growth of US unions is labor law. Private-sector union membership surged dramatically in the decade following passage of the National Labor Relations Act of 1935, and public-sector membership grew rapidly a few decades later in response to state and federal legislation that gave government workers the right to organize and bargain collectively. Similarly, subsequent legal changes (in the form of amendments and administrative rulings) have contributed to the erosion of the US labor movement. In light of the important connection between IR and the law, William B. Gould surveys key aspects of this topic, including the future of labor law reform, in Chapter 6.

Attention to the challenges associated with shoring up IR institutions within the academy is the focus of Chapters 7 and 8. In Chapter 7, Daphne Taras documents how IR is marginalized in business schools, which is the institutional home for a substantial number of IR scholars. The causes Taras identifies are the pursuit of rankings according to benchmarking systems that exclude IR journals; reliance on scoring systems that give virtually no recognition for books or book chapters; and use of reward systems that overlook the 'town-gown interactions' that have long been a tradition in IR. Her conclusion is that an extensive and coordinated effort is required to reform the academic and scholarly institutions of the field (an 
endeavor that would, for example, include collective action to establish IR professorships, obtain stable funding sources for research on work and employment matters, and better integrate IR into business-school offerings).

Chapter 8, by Immanuel Ness, Bruce Nissen and Charles Whalen, sketches a historical account of the evolution of labor and employment journals over the past century (with special attention to academically oriented publications produced in the United States). While many of the field's publications are currently reaching more readers and are resting on a more secure financial footing than in the past, the authors - all journal editors find that the IR journal landscape is actually somewhat precarious due to trends that are fragmenting the study of work and employment and causing such scholarship to become increasingly the product of a subfield within traditional disciplines. They conclude that today's IR scholars must devote more attention to producing successful, interdisciplinary journals; and they recommend that members of the field explore recent, ongoing initiatives that use electronic technologies to create new forms of scholarly communication and enhance competition in scientific publishing.

\section{THE PRACTICE OF INDUSTRIAL RELATIONS}

There is no single path to reinvigorated IR teaching and research. Nevertheless, a number of IR scholars have found strategies and methods they find promising. Chapter 9, by Michael J. Piore, discusses the approach that he and his colleagues at the Massachusetts Institute of Technology (MIT) have adopted to keep their IR curriculum intellectually stimulating and professionally relevant in an economic, social and academic environment that is quite different from that of the period immediately following World War II, when IR flourished. At MIT, IR is conceived as an interdisciplinary field that includes all aspects of work and employment, but professors also stress that insights from IR can be applied more broadly and that work-related social relations do not need to be studied in isolation from other social movements, problems and institutions. In addition, MIT's IR graduate students are required to supplement IR course work by taking the core curriculum in one of the major social-science disciplines.

Chapter 10, by Nick Wailes, Russell D. Lansbury and Jim Kitay, complements Piore's chapter by illustrating a promising path to greater IR research vitality. Their approach is similar to that recommended by Godard; indeed, Chapters 4 and 10 both draw on and extend elements of scholarship falling under the 'new institutionalism' and 'varieties of capitalism' rubrics. In Chapter 10, however, the focus is on exploring the 
relationship between economic globalization and employment relations by drawing on a research project that examines the automobile industry in seven countries.

The relationship between globalization and IR also figures prominently in Chapter 11, by Katie Quan. Her chapter, which considers the need to redesign labor relations in the global garment industry, shows the continued relevance of research that returns to the problem-solving focus that was once a core characteristic of IR scholarship. Quan also identifies innovative ways that IR scholars can use their expertise and skills to simultaneously enhance their understanding of work and employment relations and further advance real-world problem solving.

Chapter 12, by Kent Wong and Janna Shadduck-Hernández, closes Part 3 with an examination of immigrant workers and 'the new American labor movement.' By discussing the UCLA Center for Labor Research and Education, the authors explain how 'university programs that focus on supporting and repositioning immigrant workers as central players in society and within contemporary social movements hold the potential of redefining labor and industrial relations programs nationally.' While Kaufman's chapter calls for restructuring IR according to the field's original paradigm largely because he sees no resurgence of unions on the horizon, Chapter 12 points toward the revitalization of IR and the labor movement at the same time. 'The linkages and prospects of coalition building among immigrant workers (both union and nonunion), their communities and labor organizations create important opportunities for labor educators, students and universities,' write Wong and Shadduck-Hernández.

\section{THE FUTURE OF INDUSTRIAL RELATIONS}

This book is designed to foster dialogue on the future of IR as an academic enterprise, not to be a comprehensive guide or to promote the 'one best way' forward. ${ }^{2}$ Nevertheless, while the book's contributors were invited to present a personal view of the challenges and opportunities ahead for IR, a common thread emerges just the same: the vision of IR as a broad, interdisciplinary field that strives for both science building and practical problem solving. These chapters also reinforce a view of my own. Like Kaufman, I contend that part of what is necessary to advance the field is for IR scholars to reconnect with their roots.

As the editor of a journal published by the LERA, I recently reviewed some of the earliest documents of that organization - originally called the Industrial Relations Research Association (IRRA) - while preparing for its sixtieth anniversary. In the process, I was reminded that in 1948 the group's 
first president was Edwin E. Witte, an economics professor at the University of Wisconsin and a former student of John R. Commons, arguably the most influential scholar in the history of IR. ${ }^{3}$ Since the careers of Commons and Witte span perhaps the most vibrant period of US IR scholarship - including a long stretch during which organized labor accounted for a tiny fraction of the nation's labor force - I decided to expand my historical investigations and become reacquainted with various writings of Witte, Commons, and other early IR contributors. I was looking at the past to find insights that would help IR to progress in the years ahead, and I quickly learned that the early pioneers of IR seemed almost eager to oblige. My research revealed three findings.

The first finding is that Commons and Witte both grounded their IR in institutional economics, which was conceived not as a narrow discipline but as an expansive, interdisciplinary study of social problems. Indeed, institutionalism was partly an attempt at the marriage of economics and an array of disciplines, including law, sociology, political science, history and psychology. In a 1954 journal article, for example, Witte describes his conception of institutional economics: 'It is not so much a connected body of economic thought as a method of approaching economic problems. This method is what might be called a practical problems approach.' Institutional economists, he adds, are interested in studying actual economic phenomena for the purpose of social improvement, while many other economists are concerned primarily with expressing the "timeless and placeless' principles that govern the price system. Institutionalists believe in building and using theories in their work, but they insist on grounding those theories in history and institutional reality (Witte, 1954: 133-5).

The second finding is that Commons, Witte and their colleagues defined their field broadly. A Social Science Research Council report, written with the involvement of Commons, defines IR as including examinations of workers in relation to their work, their employers, their fellow workers and the public (Social Science Research Council, 1928: 22). Similarly, a 1931 report prepared by the National Industrial Conference Board states, 'The term "industrial relations" comprises every incident that grows out of the fact of employment' (quoted in Kaufman, 2004: 95, emphasis added). An early IR textbook edited by Commons devotes as much attention to 'labor management' (personnel management) as to labor unions, and also covers other issues, including both labor law and worker security (unemployment, accidents and workers' compensation, and employee health issues). Indeed, in that book (and elsewhere) Commons underscores the importance he assigns to the issue of economic security by identifying the business cycle as 'the greatest of all labor problems' (Commons, 1921: 4; see also Whalen, 1993). 
The third finding is that Witte, Commons, and even Commons's professor, Richard T. Ely (a founder of the American Economic Association), were acutely aware of the creative role that government plays in economic life. In addition to serving as president of the IRRA, Witte ascended to the presidency of the American Economic Association (AEA). In his presidential address to the AEA, Witte focused on the relationship between economics and public policy. He stressed that 'there never was a time when laissez faire prevailed in the United States' and expressed support for the preeminent plank in the 1886 platform of the AEA, which declares that its founders regarded the state 'as an agency whose positive assistance is one of the indispensable conditions of human progress' (Witte, 1957: 1, 5). As Warren J. Samuels has written about Witte's university seminars and scholarly writings on public policy, 'Foremost of Witte's conclusions was that of the inseparability of government and economy' (Samuels, 1967: 134).

In the Commons-Witte view of the state, government is much more than a regulator of economic activity. To be sure, these scholars recognized government as a rule maker and umpire, inextricably involved in the promulgation of the basic economic institutions that make capitalism or free enterprise what it is' (Samuels, 1967: 136). But they also saw government as a social partner, and envisioned it working alongside individual initiative and private enterprise in an effort to promote overall economic wellbeing. For example, quoting Abraham Lincoln, Witte wrote, 'Government should do for a people what they cannot do for themselves or that which they cannot do so well for themselves in their individual capacities.' He could have just as easily quoted Commons, who stressed that collective action involves not just coercion or control, but also the liberation and expansion of individual action. ${ }^{4}$

The problems of today are not identical to those of Commons's day, and, of course, nobody wants to turn back the clock and disregard decades of subsequent theory-building and practice, but reconnecting with IR's roots can still provide guidance for the IR scholars of today and tomorrow. The Commons-Witte insights presented above remain promising as a basis for research, teaching, and dialogue on labor and employment relations. Moreover, there is guidance to be obtained not only at a foundational or conceptual level, but also at a more practical level.

Commons's attention to the business cycle, for example, is a reminder that IR scholars have long considered human resources from a national or macroeconomic perspective. In the 1960s and 1970s, federal policymakers' attention to employment and training policies helped sustain academic interest in the nation's human resources, though, understandably, most scholars became specialists and focused on a particular labor-market segment or policy area. Although high-quality research in this area 
continues (much of it sponsored by the W.E. Upjohn Institute for Employment Research), IR scholars' interest in managing the nation's human resources has dropped considerably in recent decades and the focus has instead moved to enterprise-level human resource management. With global forces exerting a greater influence on the US labor market each year, however, the macro realm is quickly becoming an area in great need of the involvement of IR scholars. ${ }^{5}$

Since only a small fraction of recent IR scholarship has centered on unemployment, workforce development and other aspects of macrohuman resource management, it might appear convenient for IR to cede that area to economists. Doing so, however, would be a huge mistake. Although US economic policy has helped keep unemployment rates low for a number of years, much contemporary economic theory remains dismissive of the subject of unemployment (because joblessness is assumed to be a matter of individual choice). Moreover, almost the entire economics profession has ignored the fact that beyond the low rate of US unemployment are job 'offshoring' and other serious challenges - most tied to an ongoing transformation of the structure of the economy - that put financial security and a rising standard of living at risk for many working families. ${ }^{6}$

In the end, reconnecting with IR's history reveals that the field's evolution has always depended upon human decisions (this is a point CutcherGershenfeld addresses in Chapter 1). There has never been much that is inevitable about work, the way it is studied, or the makeup and vitality of the academic enterprise associated with such studies. The field's past can be a springboard, not an albatross. The conceptual, institutional and practical insights contained in the present volume can help stimulate constructive dialogue and additional creativity. And the future of IR - under that name, 'employment relations,' or some label not yet invented - can be bright. ${ }^{7}$

\section{NOTES}

1. The erosion of IR as a field of study has been particularly severe in the United States. (For discussions of IR outside the United States, see, for example, Kaufman, 2004; and Ackers and Wilkinson, 2003. According to Kaufman, there are two reasons why the field of IR stabilized in the United Kingdom in the past decade or so: union membership stabilized when the Labor Party came to power in the late 1990s and British IR broadened its domain 'to give greater room to social policy' (Kaufman, 2004, 612).)

2. Actually, this book seeks to foster the continuation of a dialogue on the future of IR. Scholars and practitioners have addressed aspects of this subject in the past, both in the pages of the Proceedings of the annual meetings of the LERA (formerly the Industrial Relations Research Association) and elsewhere (see, for example, Adams and Meltz, 1993; and Whitfield and Strauss, 1998). Most recently, scholars have collaborated to examine the future of the study of labor and employment relations by means of a focus on the 
United Kingdom (Ackers and Wilkinson, 2003) and Australia (Hearn and Michelson, 2006). This volume complements those efforts by focusing on North America, especially the United States, though many of its insights should be applicable to the study of IR in other countries.

3. Although Commons had a great impact as a professor, one must recall that the writings of Sidney and Beatrice Webb were an important influence on Commons's scholarship involving labor issues and that their works continue to be recognized as seminal to the IR literature.

4. For an extended discussion of my examination of early IR scholarship, see Whalen (2008a: 22-6). That article addresses the fact that Commons and Witte acknowledged there are dangers and challenges associated with public action, but emphasizes they ultimately concluded that government remains an inescapable fact of life. The article also gives some attention to how IR scholars can constructively contribute to shaping and promoting the public purpose.

5. In fact, there is an increasing need for greater attention to human resource development and utilization at the international level as well. Indeed, whereas early IR scholars devoted most of their energy to establishment of groups and working rules that were local and national, it will likely be necessary for twenty-first century IR scholars to fashion and improve organizations and institutions that are global.

6. For discussions of contemporary challenges facing working families in the United States, see, for example, Hacker (2006) and Whalen (2005; 2008b).

7. The author thanks Bruce Kaufman and Linda Whalen for reading this chapter in draft form and offering valuable suggestions.

\section{REFERENCES}

Ackers, Peter and Wilkinson, Adrian (2003), Understanding Work and Employment: Industrial Relations in Transition, Oxford, UK: Oxford University Press.

Adams, Roy J. and Meltz, Noah M. (1993), Industrial Relations Theory: Its Nature, Scope, and Pedagogy, Lanham, MD: The Scarecrow Press.

Budd, John W. (2004), Employment with a Human Face: Balancing Efficiency, Equity and Voice, Ithaca, NY: ILR Press.

Commons, John R. (ed.) (1921), Trade Unionism and Labor Problems, Second Series, Boston, MA: Ginn and Company.

Hacker, Jacob S. (2006), The Great Risk Shift. New York: Oxford University Press.

Hearn, Mark and Michelson, Grant (2006), Rethinking Work: Time, Space and Discourse, Melbourne, Australia: Cambridge University Press.

Kaufman, Bruce E. (2004), The Global Evolution of Industrial Relations: Events, Ideas and the IIRA, Geneva: International Labor Office.

Samuels, Warren J. (1967), 'Edwin E. Witte's concept of the role of government in the economy,' Land Economics 43 (2), 131-47.

Social Science Research Council (1928), Survey of Research in the Field of Industrial Relations, New York: Social Science Research Council.

Whalen, Charles J. (1993), 'Saving capitalism by making it good: the monetary economics of John R. Commons,' Journal of Economic Issues 27 (4), 1155-79.

Whalen, Charles J. (2005), 'Sending jobs offshore from the United States: what are the consequences?' Intervention: Journal of Economics 2 (2), 33-40.

Whalen, Charles J. (2008a), 'LERA's anniversary: an opportunity to reconnect with our roots,' Perspectives on Work, 11 (2): 22-6.

Whalen, Charles J. (2008b), 'Post-Keynesian institutionalism and the anxious 
society,' in Sandra S. Batie and Nicholas Mercuro (eds), Alternative Institutional Structures: Evolution and Impact, London: Routledge, pp. 273-99.

Whitfield, Keith and George Strauss (1998), Researching the World of Work: Strategies and Methods in Studying Industrial Relations, Ithaca, NY: ILR Press.

Witte, Edwin E. (1954), 'Institutional economics as seen by an institutional economist,' Southern Economic Journal 21 (2), 131-40.

Witte, Edwin E. (1957), 'Economics and public policy,' American Economic Review $47(1), 1-21$. 